\title{
Analysis of cases of the national maternity and childhood national center within the framework of guaranteed volume of free medical care
}

\author{
Nurzhamal Ahmadyar ${ }^{1}$ \\ ${ }^{1}$ National research center for maternal and child health \\ of the corporate fund "UMC», Astana, Kazakhstan
}

J CLIN MED KAZ 2017; 3(45 SUPPL 3):55-57 Автор для корреспонденции:Ахмадьяр Н.С. Национальный научный центр материнства и детства корпоративного фонда «UMC». Адрес:010000 , Казахстан, г. Астана, пр.Туран,32,

E-mail:Nurzhamal.Ahmadyar@umc.org.kz

\section{ABSTRACT}

Objective:analysis of the work of the new Department of health care expertise (DHCE) of the Corporate Fund «University Medical Center» in the context of confirmed defects by codes for 2015 and 1 quarter of 2016 of the treated cases of NNCMD.

Methods.Preexisting analyze of the stored nuclei in NNCMS in the single system of stationary electron registrations

Results.DHCE in a short time managed to change the structure of defects and conduct individual work with each doctor to work with the electronic register of inpatients, improve the quality of services provided, compliance with national protocols.

Conclusion:The research will allow you to create a rationalization of the DEMP, which will shorten the structural defects and carry out individual work with each other on the EHRA work, the implementation of which will be the work of the national protocols.

Keywords: analysis of health services, quality of medical services

\section{ТҰЖЫРЫМДАМА}

АНА МЕН БАЛА ҰЛТТЫҚ ҒЫЛЫМИ ОРТАЛЫҒЫНЫҢ ЖАҒДАЙЛАРЫН ТАЛДАУ ТЕГІН МЕДИЦИНАЛЫҚ ТЕГІН КУТІМГЕ КЕПІЛДІ КЕЛГЕН НЕГІЗІНДЕ

Ахмадьар Н.C. 1

${ }^{1}$ «UMC» корпоративтік қорының Ана мен бала ұлттық ғылыми орталығы, Астана, Қазақстан

Мақсаты: 2015 жылдың және 2016 жылдың 1 тоқсанына АБҰҒО ережелері бойынша бекітілген кемшіліктерді медициналық көмекке сараптама бөлімінің (ДКСБ) жаңа жұмысының тәжірибесін және талдауын жұмыстары жүргізілуде.

Зерттеудің әдістері.ННЦМД-де өткен стационарлық электронды тіркеу жүйесіндегі алдын-ала сапалы талдау

Нәтижелері: DКСБ қысқа мерзімде кемшіліктер құрылымын өзгертуге және әр дәрігермен стационардың электрондық тізілімімен жұмыс істеуге, көрсетілетін қызметтердің сапасын жақсартуға, ұлттық хаттамалардың сақталуына жеке жұмыс жүргізе алды.

Қорытынды: ДЭМП құрудың рационалдылығын жасауға мүмкіндік береді, ол қысқа мерзімде құрылымдық дефектілерді қалпына келтіріп, жеке дәрігерлермен жұмыс істеу, әртүрлі қызметтермен қамтамасыз ету, ұлттық протоколдарды сақтау.

Маңызды сөздер: медициналық қызмет сапасын жақсарту, медициналық қызмет сапасы

PEЗЮME

АНАЛИЗ ПРОЛЕЧЕННЫХ СЛУЧАЕВ НАЦИОНАЛЬНОГО НАУЧНОГО ЦЕНТРА МАТЕРИНСТВА И ДЕТСТВА В РАМКАХ ГАРАНТИРОВАННОГО ОБЪЕМА БЕСПЛАТНОЙ МЕДИЦИНСКОЙ ПОМОЩИ

Ахмадьяр Н.С. ${ }^{1}$

'Национальный научный центр материнства и детства корпоративного фонда «UMC», г. Астана, Казахстан

Цель:опыт и анализ работы нового департамента экспертизы медицинской помощи (ДЭМП) КФ «UМС» в разрезе подтвержденных дефектов по кодам за 2015 год и 1 квартал 2016 года пролеченных случаев ННЦМД

Методы:предварительный анализ пролеченных случаев в ННЦМД в единой системе электронного регистра стационарных больных

Результаты:ДЭМП в короткий срок удалось изменить структуру дефектов и провести индивидуальную работу с каждым врачом по работе с электронным регистром стационарных больных, повышению качества оказываемых услуг, соблюдение национальных протоколов.

Выводы: Данное исследование позволяет сделать вывод о рациональности создания ДЭМП, которому в короткий срок удалось изменить структуру дефектов и провести индивидуальную работу с каждым врачом по работе с ЭРСБ, повышению качества оказываемых услуг, соблюдение национальных протоколов.

Ключевые слова: анализ пролеченных случаев, качество медицинских услуг 


\section{Введение}

Национальный научный центр материнства и детства (ННЦМД) является одним из ведущих научнообразовательных и лечебно-диагностических институтов на территории Центральной Азии в области педиатрии, детской хирургии, акушерства, гинекологии и репродуктивного здоровья. Мощность клиники рассчитана на 500 коек, из них 385 педиатрических и 125 коек акушерско -гинекологических. Медицинское обслуживание проводится в 31 отделениях с современными комфортабельными условиями для пребывания пациентов. В 2015 году Центр стал одной из первых клиник на пространстве СНГ, которая подтвердила международную реаккредитацию Joint Commission International (JCI). Реаккредитация JCI подтверждает мировой класс предоставляемых медицинских услуг и является «золотым стандартом» на международной арене медицинских услуг.

С 1 января 2016 года ННЦМД вошел в состав Корпоративного Фонда «UMC». С целью внутреннего контроля качества и объема медицинской помощи был создан департамент экспертизы медицинской помощи (ДЭМП).

Что такое качество медицинской помощи? Наиболее приемлемым является определение Европейского бюро BO3: «Качество медицинской помощи - это содержание взаимодействия врача и пациента, основанное на квалификации профессионала, т.е. его способности снижать риск прогрессирования имеющегося у пациента заболевания и возникновения нового патологического процесса, оптимально использовать ресурсы медицины и обеспечивать удовлетворенность пациента от его взаимодействия с медицинской подсистемой». Качество медицинской помощи также зависит от экономических стимулов в рамках единого национальной системы здравоохранения, взаимоотношений между медицинской организацией и территориальным департаментом комитета оплаты медицинских услуг по г. Астана (КОМУ).

Целью данного исследования является анализ пролеченных случаев ННЦМД в разрезе подтвержденных дефектов по кодам за 2015год и 1 квартал 2016 года.

\section{Материалы и методы}

ДЭМП ежедневно проводит предварительный анализ пролеченных случаев в ННЦМД в единой системе электронного регистра стационарных больных (ЭРСБ) ив своей работе руководствуется следующими нормативноправовыми актами:

- Кодекс «О здоровье народа и системе здравоохранения», статья 25 пункт 3. «Возмещение затрат производится с учетом результатов контроля качества и объема оказанной медицинской помощи, осуществляемого уполномоченным органом»;

- Приказ МЗСР РК от 28 июля 2015 года №627 «Об утверждении Правил возмещения затрат организациям здравоохранения за счет бюджетных средств»;

- Приказ МЗСР РК от 17 августа 2015 года №669 «Об утверждении правил оказания стационарозамещающей помощи»;

- Приказ МЗСР РК от 29 сентября 2015 года №761 «Об утверждении правил оказания стационарной помощи»;

- Приказ МЗСР РК от 31 октября 2014 года №210 «О внесении изменении и дополнений в приказ ...№750 «Об утверждении видов ВСМП по профилям»;

- Приказ МЗСР РК от 30 декабря 2015 года №1082 «О внесении изменении и дополнений в приказ ...№725 «Об утверждении тарифов на медицинские услуги в рамках ГОБМП».

Данное исследование проведено согласно Приложению 34 К Правилам возмещения затрат организациям здравоохранения за счет бюджетных средств, где утвержден классификатор кодов по перечню случаев, подлежащих снятию и не подлежащих оплате, в том числе частично, по результатам контроля качества и объема медицинской помощи из средств республиканского бюджета. В данное приложение включено 17 кодов по которым в РГП на ПХВ «Республиканский центр электронного здравоохранения» проводит определение потенциальных дефектов в электронном формате, которые далее передаются для подтверждения в КОМУ и ККМФД. Из базы данных ЭРСБ каждый пятый пролеченный случай по ГОБМП проходит экспертизу через эксперта. Эксперты КОМУ или ККМФД изучают выписные эпикризы и при наличии кода дефекта потенциальный дефект имеет возможность стать подтверждённым с определенной суммой санкции.

\begin{tabular}{|c|c|c|c|}
\hline № & № кода & Наименование & $\begin{array}{l}\text { Подлежит снятию \% } \\
\text { от стоимости случая }\end{array}$ \\
\hline 1 & 1.1 & Случай госпитализации без медицинских показаний & $100 \%$ \\
\hline 2 & 1.2 & Случай некорректного ввода данных пациента в ЭРСБ & $10 \%$ \\
\hline 3 & 1.3 & Случай завышения уровня весового коэффициента КЗГ & $50 \%$ \\
\hline 4 & 1.4 & $\begin{array}{l}\text { случай повторного незапланированного поступления (за календарный период месяц по поводу одного и того же за- } \\
\text { болевания) }\end{array}$ & $100 \%$ \\
\hline 5 & 1.5 & Не подтверждённые случаи оказания медицинской помощи в рамках ГОБМП & $100 \%$ \\
\hline 6 & 1.6 & Случай необоснованного отклонения лечебных мероприятий от стандартов в области здравоохранения & $30 \%$ \\
\hline 7 & 1.7 & Случаи с неподтвержденными медицинскими услугами, медикаментами, изделиями медицинского назначения & $100 \%$ \\
\hline 8 & 2.1 & Обоснованные жалобы на качество оказанных медицинских услуг & $100 \%$ \\
\hline 9 & 2.2 & Привлечение медикаментов и денежных средств пациента при оказании медицинской помощи, входящей в ГОБМП & $\begin{array}{l}\text { на сумму затрат, } \\
\text { подтвержденных до- } \\
\text { кументально }\end{array}$ \\
\hline 10 & 2.3 & Случаи летальных исходов (предотвратимые) & $100 \%$ \\
\hline 11 & 2.4 & Случаи осложнений, возникших в результате лечения & \\
\hline 12 & 2.4 .1 & Случайнеобоснованного отклонения лечебных мероприятий от стандартов в области здравоохранения & $30 \%$ \\
\hline 13 & 2.4 .2 & Случай необоснованного отклонения диагностических мероприятий от стандартов в области здравоохранения & $30 \%$ \\
\hline
\end{tabular}




\begin{tabular}{|c|c|c|c|}
\hline 14 & 2.5 & Случаи с исходом заболевания «ухудшение» & \\
\hline 15 & 2.5 .1 & Случай необоснованного отклонения лечебных мероприятий от стандартов в области здравоохранения & $30 \%$ \\
\hline 16 & 2.5 .2 & Случай необоснованного отклонения диагностических мероприятий от стандартов в области здравоохранения & $30 \%$ \\
\hline 17 & 2.6 & Случаи с исходом заболевания «без перемен» & \\
\hline 18 & 2.6 .1 & Случай необоснованного отклонения лечебных мероприятий от стандартов в области здравоохранения & $20 \%$ \\
\hline 19 & 2.6 .2 & случай необоснованного отклонения диагностических мероприятий от стандартов в области здравоохранения & $20 \%$ \\
\hline 20 & 2.7 & Случаи расхождения клинического и морфологического диагнозов & $50 \%$ \\
\hline
\end{tabular}

\section{Результаты и обсуждение}

В АО «ННЦМД» в 2015 году по данным ЭРСБ (кроме онкологии 2) было пролечено более 12 тысяч пациентов по ГОБМП и из них выявлено 3,5\% подтвержденных дефекта, из них:

1. в педиатрическом блоке - $41 \%$ :

2. в акушерско-гинекологическом блоке - $21 \%$;

3. в дневном стационаре $38 \%$.

Среди дефектов наиболее часто встречаемый в ННЦМД код 1.5 неподтвержденный случай. По этому коду было предъявленштраф на $38 \%$ пролеченных случаев.

Далее,среди дефектов по частоте превалируют коды:

- 1.6 отклонения от лечебно-диагностических мероприятий от стандартов- $28 \%$;

- 1.2 некорректный ввод данных пациента-26\%;

- 1.3 случаи завышения КЗГ-7\%.

При изучении ежемесячной динамики подтвержденных дефектов мы не нашли прямой связи с количеством пролеченных пациентов. Так, наибольшие удержания финансовых средств (в тенге)были осуществленыв феврале $17,7 \%$, январе $15,0 \%$, мае $12,2 \%$ и в апреле $11,9 \%$ месяцах.

Что касается подтвержденных дефектов ННЦМД в феврале 2016 года, то КОМУ выставил штрафные санкции по подтвержденным дефектам, из них по кодам 1.3- случаи завышения КЗГ - 28\% случаев, 1.2 некорректный ввод данных пациента - 24\% и по 16\% - 1.1 необоснованная госпитализация и 1.6 - отклонения от лечебнодиагностических мероприятий от стандартов.

\section{Вывод}

Таким образом, данное исследование позволяет сделать вывод о рациональности создания ДЭМП, которому в короткий срок удалось изменить структуру дефектов и провести индивидуальную работу с каждым врачом по работе с ЭРСБ, повышению качества оказываемых услуг, соблюдение национальных протоколов. Результаты деятельности ДЭМП кроме того являются основой для претензионной работы с КОМУ.

\section{Литература}

1. Prikaz MZSR RK «Ob utverzhdenii Pravil vozmeshhenija zatrat organizacijam zdravoohranenija za schet bjudzhetnyh sredstv». [in Russian]. ot 28 ijulja 2015; (627). 